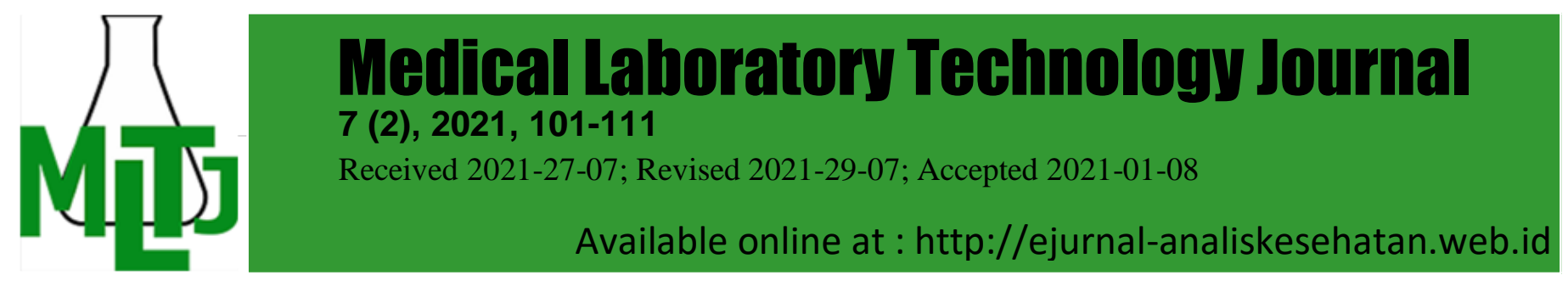

\title{
Risk Of Malignancy Index 4 Performance as a Predictor Advanced Stage Epithelial Ovarian Carcinoma Used for Neoadjuvant Chemotherapy
}

\author{
*Tatit Nurseta1, Dhian Eka Putri Harnandari', Putu Arik Herliawati², Mukhamad \\ Nooryanto ${ }^{1}$, Puspita Handayani ${ }^{1}$
}

${ }^{1}$ Department of Obstetrics and Gynecology, Faculty of Medicine, University Brawijaya, Indonesia. ${ }^{2}$ Master of Midwifery, Faculty of Medicine, University Brawijaya, Indonesia *Email : tns_onko.fk@ub.ac.id DOI: $10.31964 / \mathrm{mltj} . \mathrm{v0i0} .394$

\begin{abstract}
The relatively low survival rate in patients with advanced-stage carcinoma ovaries requires early detection to improve treatment outcomes. The method currently used to determine the administration of neoadjuvant chemotherapy is ascites cytology and laparoscopic. This study aims to find a non-invasive technique in determining preoperative Neoadjuvant Chemotherapy administration, and that method can use as a predictor of advanced epithelial ovarian carcinoma. The benefit of this study is to help clinicians consider administering neoadjuvant chemotherapy with a Risk Of Malignancy Index 4 score. An analytical observational study with a retrospective crosssectional type study with samples of all patients from January 2016 to January 2020 diagnosed at the dr. Saiful Anwar Hospital in Malang indonesia. The number of initial samples of this study is 106 samples. Between the results of the Risk Of Malignancy Index 4 score and the histopathological results, it finds that the $p$-value was less than $0.05(p<0.05)$ indicates that the Risk Of Malignancy Index 4 score is very good for predicting advanced epithelial ovarian carcinoma. With a sensitivity of $86,2 \%$, specificity of $87,5 \%$, the cut of value Risk Of Malignancy Index 4 to be a predictor of advanced ovarian carcinoma is 2982. This study indicates that the Risk Of Malignancy Index 4 score is excellent for predicting the stage of Epithelial Ovarian Carcinoma. This cut-off value can reference preoperative neoadjuvant therapy to avoid morbidity and mortality due to the high risk of surgery.
\end{abstract}

Keywords: Risk of malignancy index; ovarian carcinoma; advanced stage; diagnostic test; neoadjuvant chemotherapy.

\section{INTRODUCTION}

Worldwide, ovarian carcinoma has the highest mortality rate of all gynecologic malignancies (Mutch and Prat 2014). According to WHO/IARC (International Agency for Research on Cancer), the incidence of ovarian carcinoma in Indonesia ranks second after cervical carcinoma with an incidence rate of 9664 cases in 2008 (Loomis, Huang, and Chen 2014). The high morbidity and mortality rate is related to the complications found in the operation of patients with advanced ovarian carcinoma who underwent surgery without neoadjuvant chemotherapy, including adhesions, organ injury, and bleeding (Worley Jr et al. 2013).

The standard primary therapy for patients with advanced ovarian carcinoma is primary debulking surgery followed by adjuvant chemotherapy with Carboplatin and Paclitaxel (Pignata et al., 2011). Debulking considers optimal if the residue left is $1 \mathrm{~cm}$ in size. The increasing morbidity and mortality of debulking performed in the context 
of proving an ovarian carcinoma at an early stage is a dilemma. Therefore, neoadjuvant chemotherapy use for primary ovarian carcinoma, which predicts to be less likely to achieve optimal cytoreduction if surgery performs (Fauziah and Andrijono, 2007). Patients with poor performance status, who are at high risk for morbidity and mortality if cytoreduction surgery performs, can also be given multiple cycles and standard chemotherapy before surgery so that subsequent cytoreduction surgery will be safer (Chan et al., 2003).

Neoadjuvant Chemotherapy (NACT) in advanced epithelial ovarian cancer is the last concept to discuss to treat progressive disease. Neoadjuvant implies the administration of chemotherapy before cytoreductive surgery. So far, the procedure for determining the administration of NACT still bases on two methods, namely ascites cytology and laparoscopy. And the requirement for giving NACT is to attach the results of the Anatomical Pathology laboratory (Baransi et al. 2020).

Ankara Maternity Hospital Turkey has conducted a study to assess neoadjuvant chemotherapy as an alternative to surgery in the initial treatment of bulky ovarian tumors. Neoadjuvant chemotherapy followed by debulking laparotomy has not been shown to worsen the prognosis but instead reduces aggressive surgery and improves the quality of life (Lu et al. 2001).

The multiparametric Risk of Malignancy Index (RMI) score can be a valuable tool in predicting ovarian malignancy in areas with limited resources. The Risk of Malignancy Index (RMI), which considers serum CA-125 levels, menopausal status, and ultrasound findings in predicting malignant pelvic masses, is widely used in developed countries (Aziz and Najmi 2015). Yamamoto in 2009, who confirmed that RMI 4 is more reliable than RMI 1, RMI 2, and RMI 3 (Yamamoto et al. 2014). However, there are no studies that indicate early-stage and advanced-stage ovarian carcinoma from an RMI 4. Previously, many researchers had developed this RMI but were only limited to distinguishing benign and malignant adnexal tumors (Campos et al. 2016) (Akker van den et al. 2016) (Ulusoy et al. 2007) (Clarke et al. 2009). This research is the first study to develop the RMI score as a predictor of advanced stage. No previous studies are looking for non-invasive methods as a consideration for giving NACT. The purpose of this study is to find a non-invasive way to assist clinicians in considering the administration of NACT with a method that is simple, fast, and does not require high costs.

\section{MATERIALS AND METHOD}

This study uses an analytical observational research design type crosssectional study; in this study, the researchers tried to find the relationship between variables, namely by analyzing the data collected-this study conduct in April 2021. The sample population is all populations suffering from ovarian malignancy in the oncology department of the Department of Obstetrics Gynecology dr. Saiful Anwar Hospital Malang Indonesia. The research sample was taken with a retrospective study, data collection from the medical record of patients suffering from ovarian malignancies for the last five years, from January 2016 until January 2020. Based on data obtained from 5 years, 253 patients had ovarian carcinoma after all the medical records were searched; based on the inclusion and exclusion criteria, 106 samples get.

Samples also take from the Anatomical Pathology Laboratory of dr. Saiful Anwar Hospital Malang. This research was approved by the Ethics committee of general hospital dr. Saiful Anwar Malang, with regards to the protection of human rights and welfare in medical research, has carefully reviewed the research protocol entitled with the number of registration 400/260/K.3/302 /2020. After all medical 
records of patients suffering from ovarian carcinoma were collected, a data collection sheet containing the necessary medical record data such as age, patient demographics, menopausal status, CA 125 levels, ultrasound results, and histopathology results.

In this study, data analysis techniques were used to measure the Risk Malignancy Index 4 (RMI4) accuracy, assessed by positive predictive value, negative predictive value, sensitivity, specificity, and accuracy value. The ROC curve uses to determine the cut-off value of RMI4 with histopathological appearance according to advanced-stage ovarian carcinoma. This statistical analysis uses SPSS version 25.0, To get all these accuracy values using a statistical test of the ROC curve and characteristic data using chi-square.

\section{RESULTS AND DISCUSSION}

Based on the polyclinic oncology and anatomic pathology laboratory data for the previous five years there is 253 patients had ovarian carcinoma. After all the medical records were searched, based on the inclusion and exclusion criteria, 106 samples obtain. Then performed staging by oncology clinician, obstetrics and gynecology department of dr. Saiful Anwar Hospital obtains as many as 48 samples suffering from early stages and 58 samples suffering from advanced stages. The characteristics of this research sample can see in tables 1 and 2 .

\section{Subject Characteristics}

Based on the table regarding the study sample characteristics, it shows that of the 48 early-stage patients, the majority are 41-50 years old, and the majority of 58 patients are 51-60 years old. Using the Chi-Square t-test, obtained a p-value of 0.008 $(p<0.05)$, indicating a statistically significant age difference. This result suggests that the age group of patients with advanced-stage Epithelial Ovarian Carcinoma is older than the group of patients with early Epithelial Ovarian Carcinoma.

Based on the characteristics of education, it was shown that in the early-stage Epithelial Ovarian Carcinoma patient group, most of the patients had high school education, namely $19(39.6 \%)$ and in the group of advanced Epithelial Ovarian Carcinoma patients with junior high school education, 24 (41.4\%) patients. Using the Chi-Square test, a $p$-value of 0.521 ( $p>0.05)$ obtains, which explains no difference in educational characteristics between the two groups of patients. Likewise, the characteristics of marital status, parity, family planning, BMI, Family History of Tumors, and menstrual cycles in both groups were relatively the same $(p>0.05)$.

Based on the characteristics of ascites and papillae, the $p$-value was less than $0.05(p<0.05)$, proving that there are differences in the characteristics of the two groups of patients. Patients with advanced epithelial ovarian carcinoma have more ascites and papillae than patients with early-stage epithelial ovarian carcinoma.

Based on the characteristics of the septa and tumor size, a p-value of $>0.005$ obtains, which means that there was no significant difference in patients with early and advanced epithelial ovarian carcinoma compared to the characteristics of the ultrasound septa and tumor size.

Based on the characteristics of the septa and tumor size, a $p$-value of $>0.005$ obtains, which means that there was no significant difference in patients with early and advanced epithelial ovarian carcinoma compared to the ultrasound septa and tumor size characteristics. 
Table 1. Sample Demographic Characteristics Table

\begin{tabular}{|c|c|c|c|}
\hline \multirow{2}{*}{ Characteristic } & \multicolumn{2}{|c|}{$\begin{array}{c}\text { Epithelial ovarian carcinoma } \\
\text { Stage }\end{array}$} & \multirow{2}{*}{ p-value } \\
\hline & $\begin{array}{l}\text { Early } \\
(n=48)\end{array}$ & $\begin{array}{l}\text { Advance } \\
(\mathrm{n}=58)\end{array}$ & \\
\hline $\begin{array}{l}\text { Age } \\
20-30 \text { years } \\
31-40 \text { years } \\
41-50 \text { years } \\
51-60 \text { years } \\
61-70 \text { years } \\
71-80 \text { years }\end{array}$ & $\begin{array}{c}4(8.3 \%) \\
7(14.6 \%) \\
25(52.1 \%) \\
9(18.8 \%) \\
1(2.1 \%) \\
2(4.2 \%)\end{array}$ & $\begin{array}{c}1(1.7 \%) \\
6(10.3 \%) \\
17(29.3 \%) \\
26(44.8 \%) \\
7(12.1 \%) \\
1(1.7 \%)\end{array}$ & $0.008^{* *}$ \\
\hline $\begin{array}{l}\text { Education } \\
\text { Elementary } \\
\text { school } \\
\text { Junior high school } \\
\text { Senior high } \\
\text { school } \\
\text { Univeristy }\end{array}$ & $\begin{array}{c}13(27.1 \%) \\
15(31.3 \%) \\
\\
19(39.6 \%) \\
1(2.1 \%)\end{array}$ & $\begin{array}{c}13(22.4 \%) \\
24(41.4 \%) \\
21(36.2 \%) \\
0(0 \%)\end{array}$ & 0.521 \\
\hline $\begin{array}{l}\text { Married Status } \\
\text { Single } \\
\text { Married once } \\
\text { Married more } \\
\text { than once }\end{array}$ & $\begin{array}{c}5(10.4 \%) \\
37(77.1 \%) \\
6(12.5 \%)\end{array}$ & $\begin{array}{c}4(6.9 \%) \\
40(69 \%) \\
\\
14(24.1 \%) \\
\end{array}$ & 0.286 \\
\hline $\begin{array}{l}\text { Parity } \\
\text { Nuliparous } \\
\text { Multiparous }\end{array}$ & $\begin{array}{l}17(35.4 \%) \\
31(64.6 \%)\end{array}$ & $\begin{array}{l}15(25.9 \%) \\
43(74.1 \%)\end{array}$ & 0.286 \\
\hline $\begin{array}{l}\text { Contraception } \\
\text { Not Yet } \\
\text { Already }\end{array}$ & $\begin{array}{c}9(18.8 \%) \\
39(81.3 \%)\end{array}$ & $\begin{array}{l}10(17.2 \%) \\
48(82.8 \%)\end{array}$ & 0.840 \\
\hline $\begin{array}{l}\text { BMI } \\
\text { Underweight } \\
\text { Normal } \\
\text { Overweight }\end{array}$ & $\begin{array}{c}18(37.5 \%) \\
23(47.9 \%) \\
7(14.6 \%)\end{array}$ & $\begin{array}{c}33(56.9 \%) \\
21(36.2 \%) \\
4(6.9 \%)\end{array}$ & 0.110 \\
\hline $\begin{array}{l}\text { Family history of } \\
\text { Cancer } \\
\text { Denied } \\
\text { Be Found }\end{array}$ & $\begin{array}{l}\text { Gynecologic } \\
\qquad 6 \text { (95.8\%) } \\
2(4.2 \%)\end{array}$ & $\begin{array}{c}55(94.8 \%) \\
3(5.2 \%)\end{array}$ & 0.808 \\
\hline $\begin{array}{l}\text { NACT History } \\
\text { Not Yet } \\
\text { Already }\end{array}$ & $\begin{array}{c}42(87.5 \%) \\
6(12.5 \%)\end{array}$ & $\begin{array}{l}31(53.4 \%) \\
27(46.6 \%)\end{array}$ & $0.000^{\star *}$ \\
\hline $\begin{array}{l}\text { Menstrual cycle } \\
\text { Regular } \\
\text { Not Regular }\end{array}$ & $\begin{aligned} & 44(91.7 \%) \\
& 4(8.3 \%) \\
&\end{aligned}$ & $\begin{array}{c}56(96.6 \%) \\
2(3.4 \%) \\
\end{array}$ & 0.279 \\
\hline
\end{tabular}


Table 2. Characteristics Table of Ultrasonographic Variables

\begin{tabular}{|c|c|c|c|}
\hline \multirow{2}{*}{ Variabel USG } & \multicolumn{2}{|c|}{$\begin{array}{l}\text { Epithelial ovarian } \\
\text { carcinoma Stage }\end{array}$} & \multirow{2}{*}{ p-value* } \\
\hline & $\begin{array}{c}\text { Early } \\
(\mathrm{n}=48)\end{array}$ & $\begin{array}{c}\text { Advance } \\
(\mathrm{n}=58)\end{array}$ & \\
\hline \multicolumn{4}{|l|}{ Asites } \\
\hline Not Found & 36 (75\%) & 18 (31\%) & $0.000^{\star *}$ \\
\hline Found & $12(25 \%)$ & 40 (69\%) & \\
\hline \multicolumn{4}{|l|}{ Papil } \\
\hline Not Found & $33(68.8 \%)$ & $26(44.8 \%)$ & $0.014^{\star \star}$ \\
\hline Found & 15 (31.3\%) & 32 (55.2\%) & \\
\hline \multicolumn{4}{|l|}{ Septa } \\
\hline Not Found & $18(37.5 \%)$ & 24 (41.4\%) & 0.684 \\
\hline Found & $30(62.5 \%)$ & $34(58.6 \%)$ & \\
\hline \multicolumn{4}{|l|}{ Solid Part } \\
\hline Not Found & 21 (43.8\%) & $11(19 \%)$ & $0.006^{\star *}$ \\
\hline Found & 27 (56.3\%) & 47 (81\%) & \\
\hline \multicolumn{4}{|c|}{ Metastasis Intra Abdomen } \\
\hline Not Found & 48 (100\%) & 51 (87.9\%) & $0.013^{\star *}$ \\
\hline Found & $0(0 \%)$ & $7(12.1 \%)$ & \\
\hline \multicolumn{4}{|l|}{ Tumor Size } \\
\hline$<7$ & $0(0 \%)$ & 2 (3.4\%) & 0.194 \\
\hline$>=7$ & $48(100 \%)$ & 56 (96.6\%) & \\
\hline
\end{tabular}

${ }^{*}$ Chi-square test results

${ }^{* *} \mathrm{p}$-value have significance effect with marks

\section{Curve ROC RMI 4}

Determination of Cut Off Value RMI4 to predict Epithelial Ovarian Carcinoma Advanced stage can be measured using the ROC curve. the ROC curve of the RMI4 score can see in figure 1.

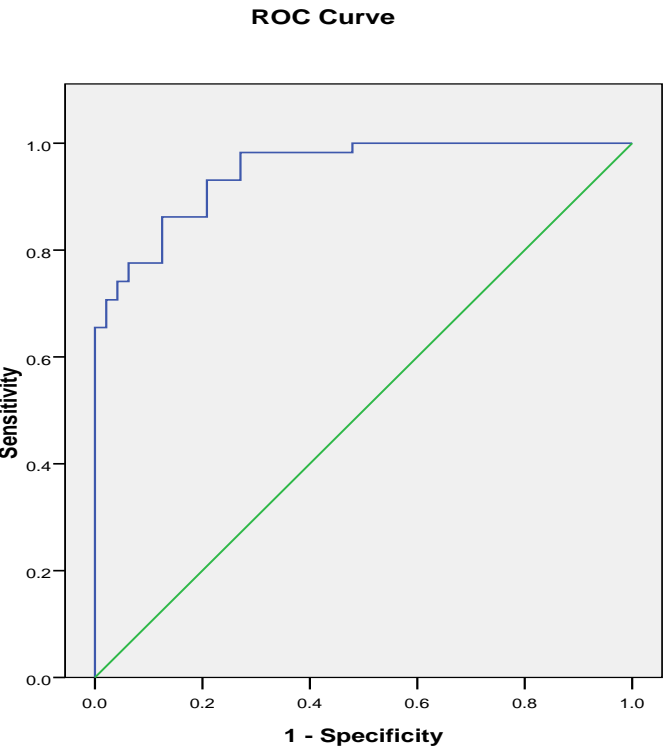

Figure 1. Determination of the RMI4 Cut Off Value is Measured Using the ROC Curve 
Table 3. Area of the ROC Curve, P-Value , $\mathrm{Cl}$ of Score RMI4

\begin{tabular}{llll}
\hline Variable & Area & p-value & $95 \% \mathrm{Cl}$ \\
\hline RMI 4 & 0.948 & 0.000 & $0.912-0.984$ \\
\hline
\end{tabular}

Based on table 3 above, the predicted results of the RMI4 score in predicting advanced-stage Epithelial Ovarian Carcinoma obtained a p-value of less than 0.05 $(p<0.05)$ with an area of 0.948 and $95 \% \mathrm{Cl}$ of $0.912-0.984$. A P-value less than 0.05 indicates that the RMI4 score is very good to use in predicting the stage of Epithelial Ovarian Carcinoma.

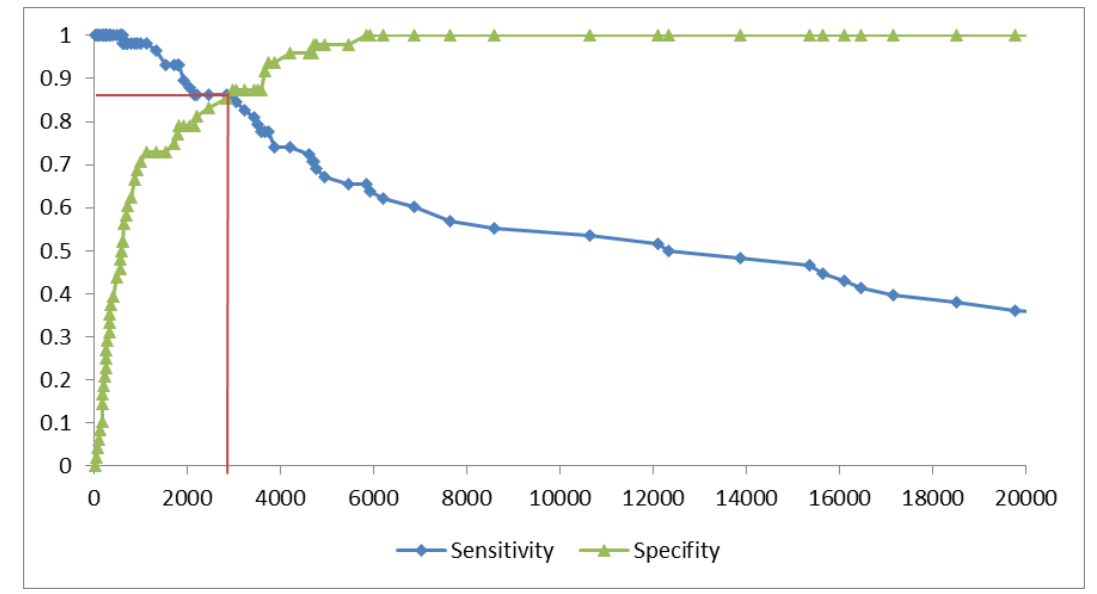

Figure 2. Sensitivity and Specificity Plot from Cut-off Value RMI4 Skor Score, the Red Line Shows the Intersection of the Sensitivity and Specificity Values of RMI4

Based on Figure 2, a plot between the sensitivity and specificity values of the RMI 4 score shows. As explained in the figure, it shows that there is an intersection of the sensitivity and specificity values. The intersection point obtains from the combination of the highest sensitivity and specificity values. The sensitivity and specificity values in the appendix show that the highest combination of sensitivity and specificity values locates at the RMI 4 point of 2982 . At that point, the sensitivity value is $86,2 \%$, and specificity is $87,5 \%$. Thus, the cut-off value of the RMI4 score to determine advanced epithelial ovarian carcinoma is 2982.

The accuracy of RMI 4 in predicting the stage of ovarian epithelial carcinoma can be done by calculating the Positive Predictive Value (PPV), Negative Predictive Value (NPV), and Accuracy value. These coefficients calculate by comparing the predicted results of RMI 4 with the results of histopathological examination. In this study, the accuracy level was measured by comparing 4 RMI 4 cut-off points. The results of calculating the RMI 4 accuracy level in predicting advanced-stage epithelial ovarian carcinoma at four cut-off points can see in table 4.

The four cut-off points show that RMI 4 with a cut-off point of 2982 has the highest PPV, NPV, and accuracy values. This test proved that RMI 4 of 2982 was more appropriate to use as a cut-off point predictor of advanced epithelial ovarian carcinoma.

RMI 4 Accuracy Level as a Predictor of Advanced Epithelial Ovarian Carcinoma

The accuracy of RMI4 in predicting the stage of Epithelial Ovarian Carcinoma can be done by calculating the Positive Predictive Value (PPV), Negative Predictive Value (NPV), and the accuracy value. The PPV, NPV, and accuracy value calculate by comparing the predicted results of RMI4 with histopathological examination results. 
The results of calculating the RMI4 accuracy level in predicting the stage of Epithelial Ovarian Carcinoma can see in table 5.

Tabel 4. Comparison of Sensitivity, Specificity, NPV, PPV, and Accuracy Values of the Four Scores that are Close to the Ideal Cut-off Value

\begin{tabular}{|c|c|c|c|c|c|c|c|}
\hline \multirow[b]{2}{*}{ Score RMI 4} & \multicolumn{2}{|c|}{ Gold Standart } & \multirow{2}{*}{$\begin{array}{l}\text { Sensit } \\
\text { iffity } \\
(\%)\end{array}$} & \multirow{2}{*}{$\begin{array}{l}\text { Specifit } \\
y(\%)\end{array}$} & \multirow{2}{*}{$\begin{array}{l}\text { PPV } \\
(\%)\end{array}$} & \multirow[b]{2}{*}{$\begin{array}{l}\text { NPV } \\
(\%)\end{array}$} & \multirow[b]{2}{*}{$\begin{array}{l}\text { Accura } \\
y(\%)\end{array}$} \\
\hline & $\begin{array}{l}\text { Early } \\
\text { Stage }\end{array}$ & $\begin{array}{l}\text { Advance } \\
\text { Stage }\end{array}$ & & & & & \\
\hline \multicolumn{8}{|l|}{$\begin{array}{l}\text { Cut Off Point }= \\
2836.6\end{array}$} \\
\hline $\begin{array}{l}\text { - Early } \\
\text { - Advance }\end{array}$ & $\begin{array}{c}41 \\
(83.7 \%) \\
7 \\
(12.3 \%)\end{array}$ & $\begin{array}{c}8 \\
(16.3 \%) \\
50 \\
(87.7 \%)\end{array}$ & 86.2 & 85.4 & 87.7 & 83.7 & 85.8 \\
\hline \multicolumn{8}{|c|}{$\begin{array}{l}\text { Cut Off Point }= \\
2982\end{array}$} \\
\hline $\begin{array}{l}\text { - Early } \\
\text { - Advance }\end{array}$ & $\begin{array}{c}42 \\
(84 \%) \\
6 \\
(10.7 \%)\end{array}$ & $\begin{array}{c}8 \\
(16 \%) \\
50 \\
(89.3 \%)\end{array}$ & 86.2 & 87.5 & 89.3 & 84.0 & 86.8 \\
\hline \multicolumn{8}{|c|}{$\begin{array}{l}\text { Cut Off Point }= \\
3056.2\end{array}$} \\
\hline $\begin{array}{l}\text { - Early } \\
\text { - Advance }\end{array}$ & $\begin{array}{c}42 \\
(82.4 \%) \\
6 \\
(10.9 \%)\end{array}$ & $\begin{array}{c}9 \\
(17.6 \%) \\
49 \\
(89.1 \%)\end{array}$ & 84.5 & 87.5 & 89.1 & 82.4 & 85.8 \\
\hline \multicolumn{8}{|l|}{$\begin{array}{l}\text { Cut Off Point }= \\
3228.4\end{array}$} \\
\hline $\begin{array}{l}\text { - Early } \\
\text { - Adavance }\end{array}$ & $\begin{array}{c}42 \\
(80.8 \%) \\
6 \\
(11.1 \%) \\
\end{array}$ & $\begin{array}{c}10 \\
(19.2 \%) \\
48 \\
(88.9 \%) \\
\end{array}$ & 82.8 & 87.5 & 88.9 & 80.8 & 84.9 \\
\hline
\end{tabular}

Table 5. RMI 4 Accuracy Rate as a Predictor of Advanced Stage Epithelial Ovarian Carcinoma

\begin{tabular}{|c|c|c|c|c|c|}
\hline \multirow[b]{2}{*}{ Score } & \multicolumn{2}{|c|}{ Gold Standart } & \multirow[b]{2}{*}{$\begin{array}{l}\text { PPV } \\
(\%)\end{array}$} & \multirow[b]{2}{*}{$\begin{array}{l}\text { NPV } \\
(\%)\end{array}$} & \multirow{2}{*}{$\begin{array}{l}\text { Accuracy } \\
(\%)\end{array}$} \\
\hline & $\begin{array}{l}\text { Early } \\
\text { Stage }\end{array}$ & $\begin{array}{c}\text { Advance } \\
\text { Stage }\end{array}$ & & & \\
\hline \multicolumn{6}{|l|}{ RMI 4} \\
\hline - Early & $\begin{array}{c}42 \\
(87.5 \%)\end{array}$ & $\begin{array}{c}8 \\
(13.8 \%)\end{array}$ & 89.2 & 84.0 & 86,8 \\
\hline - Advance & $\begin{array}{c}6 \\
(12.5 \%)\end{array}$ & $\begin{array}{c}50 \\
(86.2 \%)\end{array}$ & & & \\
\hline
\end{tabular}

Based on the analysis table using the contingency coefficient of the relationship between the results of RMI 4 and histopathological results, the positive predictive 
value (PPV) was $89.2 \%$, and the negative predictive value was $84.0 \%$. And the accuracy value is $86,8 \%$.

The International Agency for Research on Cancer states that the incidence of ovarian carcinoma in Indonesia ranks second most after cervical carcinoma with an incidence rate of 9664 cases in 2008, with the age group suffering from ovarian carcinoma the most being the age group 41 to 50 years, which is $62.7 \%$. And at least 31 to 40 years, which is as much as 10.8\% (Loomis, Huang, and Chen 2014).

The age of women diagnosed with early-stage ovarian carcinoma is mainly in the age group of 41-50 years, and from 58 women who included in the advanced stage, the most are in the age group of 51-60 years (Table 1). Statistical analysis obtained a $p$-value of 0.008 where the $p$-value is smaller than 0.05 , which indicates a significant difference and indicates that the age group of women with advanced-stage ovarian carcinoma is older than the group of women with early stage. The results obtained in this study are in line with a retrospective study conducted in Wales, United Kingdom, in which 247 women with ovarian carcinoma were at an average age of 58.09 (Abdulrahman Jr, McKnight, and Singh 2014). Meanwhile, based on the Holland-Frei Cancer Medicine 6th edition, the mean age of patients diagnosed with ovarian epithelial carcinoma is between the ages of 60 and 65 years (Berek and Bast Jr 2003). The mean age of women with ovarian epithelial carcinoma in this study is also in line with research conducted at the RSSA gynecology poly oncology in 2019, $54.2 \pm 10.3$ (Nurseta et al. 2020).

This study revealed that in women diagnosed with ovarian carcinoma in January 2016-January 2020, the highest proportion find in the multiparous patient group, namely $31(64.6 \%)$ in the early stage and $43(74.1 \%)$ in the advanced stage (Table 1$)$. It showed no difference in parity characteristics with the incidence of ovarian carcinoma $(p=0.286)$. The results of this study are not in line with some case controls showing that multiparous women have a $30-60 \%$ lower risk of ovarian cancer. Increased parity is associated with a reduced risk of ovarian malignancy (Montes et al., 2012). It is also not by the results of studies that say pregnancy reduces the risk of ovarian tumor malignancy by 19\% (McGuire 2016).

This study did not show a significant relationship between contraceptive use and ovarian tumor malignancy. This result could be due to the distribution of contraceptive users in a small sample. The number of women in this study mainly was never used contraception, namely $87(82.1 \%)$ based on table 1 . The use of oral contraceptives for more than three years is known to reduce the risk of ovarian tumor malignancy compared to women who do not use or only use it in the short term. Each of the contraceptive methods examined reduced the risk of ovarian cancer compared with the use of no artificial contraception (Ness et al., 2011).

The high morbidity and mortality rate is related to the complications found in the operation of patients with advanced ovarian carcinoma who underwent surgery without neoadjuvant chemotherapy, including adhesions, organ injury, and bleeding. The incidence of vascular injury reports being $0.04 \%$ to $0.5 \%$. Gastrointestinal injuries description in $0.13 \%$, including small intestine (55.8\%), large intestine (38.6\%), and gastric (3.9\%) (Worley Jr et al. 2013).

This study proves that RMI 4 can use as a predictor of advanced epithelial ovarian carcinoma with a $\mathrm{p}$-value $<0.05$ and a positive predictive value (PPV) of $89.3 \%$, and a negative predictive value of $84.0 \%$. The best cut-off point value as a predictor of advanced epithelial ovarian carcinoma find at 2982, with a sensitivity of $82 \%$, specificity $87,5 \%$, positive predictive value (PPV) of $89.3 \%$, and negative predictive value (NPV) of $84 \%$ (Table 4). The study conducted by Tingulstad modified 
the RMI and defined RMI 4, and they observed that at the cut-off level of 450, the sensitivity and specificity were $71 \%$ and $92 \%$ (Fainbaum and Batista 2017). This level of accuracy is in line with a study involving 548 female patients; they calculated an RMI with a cut-off point of 200 , where there were sensitivity, specificity, PPV, and NPV of $81 \%, 85 \%, 48 \%$, and $96 \%$, respectively (Campos et al. 2016). In another study, which used 100 female patients with ovarian carcinoma with a cut-off point of 450, the sensitivity, specificity, PPV, and NPV were $90 \%, 89 \%, 96 \%$, and $78 \%$, respectively (Ulusoy et al. 2007).

In the study group, Aktürk stated no statistically significant differences in identifying different malignancy risk indices between RMI 1, RMI 2, RMI 3, and RMI 4 (Aktürk et al. 2011). This study is also in line with a survey conducted by Milan Terzic. He said that the efficacy of RMI has been validated in many studies and has proven to be a simple, low-cost, and effective tool for triage management of ovarian carcinoma (Terzic et al., 2013). The sensitivity of RMI 4 indicates that it can label malignant tumors in high-risk cases, while its specificity demonstrated that it could label benign tumors as low-risk cases. It was the best result when all the parameters examined sensitivity, specificity, PPV, and NPV were high (Clarke et al., 2009).

The advantage of this study is that the results can use as a new regulation in an integrated oncology gynecology referral hospital in consideration of giving NACT with the first non-invasive method. The main limitation of this study is the retrospective design. A future retrospective study is likely to have fewer potential data sources and confounders. The medical record completeness factor also affects the number of samples obtained because most of the required data is missing.

\section{CONCLUSION}

In conclusion, the results of this study indicate that the RMI4 score is very good to use in predicting the stage of Epithelial Ovarian Carcinoma. The best cut-off point RMI 4 can be used as a reference limit to determine advanced stage Epithelial Ovarian Carcinoma is 2982. Neoadjuvant Chemotherapy (NACT) in advanced epithelial ovarian cancer is the last concept that needs to discuss to treat progressive disease. Neoadjuvant implies the administration of chemotherapy before cytoreductive surgery. It hopes that this cut-off value can be a reference for preoperative neoadjuvant therapy to avoid morbidity and mortality due to the high risk of surgery. And this non-invasive method can be a consideration for clinicians in determining the administration of NACT.

\section{ACKNOWLEDGEMENT}

We gratefully acknowledge Dr. dr. Tatit Nurseta Sp.OG (K)-Oncogyn is the main research of this study.

\section{CONFLICT OF INTEREST}

All authors state that there is no conflict or problem with any party in the writing of this journal publication.

\section{REFERENCES}

Abdulrahman Jr, Ganiy Opeyemi, Liam McKnight, and Kerryn Lutchman Singh. 2014. The Risk of Malignancy Index (RMI) in Women with Adnexal Masses in Wales. Taiwanese Journal of Obstetrics and Gynecology 53(3): 376-81.

Akker van den, Petronella A J et al. 2016. Use of Risk of Malignancy Index to Indicate Frozen Section Analysis in the Surgical Care of Women with Ovarian Tumors. 
International Journal of Gynecology \& Obstetrics 133(3): 355-58.

Aktürk, Erhan et al. 2011. Comparison of Four Malignancy Risk Indices in the Detection of Malignant Ovarian Masses. Journal of gynecologic oncology 22(3): 177.

Aziz, Aliya B, and Nida Najmi. 2015. Is Risk Malignancy Index a Useful Tool for Predicting Malignant Ovarian Masses in Developing Countries? Obstetrics and gynecology international 2015: 1-5.

Baransi, Saher et al. 2020. The Accuracy of Ascites Cytology in Diagnosis of Advanced Ovarian Cancer in Postmenopausal Women Prior to Neoadjuvant Chemotherapy. Menopause 27(7): 771-75.

Berek, Jonathan S, and Robert C Bast Jr. 2003. Epithelial Ovarian Cancer. In HollandFrei Cancer Medicine. 6th Edition, BC Decker.

Campos, Camila et al. 2016. Performance of the Risk of Malignancy Index for Discriminating Malignant Tumors in Women with Adnexal Masses. Journal of Ultrasound in Medicine 35(1): 143-52.

Chan, Y M, T Y Ng, Hextan Y S Ngan, and L C Wong. 2003. Quality of Life in Women Treated with Neoadjuvant Chemotherapy for Advanced Ovarian Cancer: A Prospective Longitudinal Study. Gynecologic oncology 88(1): 9-16.

Clarke, Sharon E et al. 2009. Risk of Malignancy Index in the Evaluation of Patients with Adnexal Masses. Journal of obstetrics and gynaecology Canada 31(5): 44045.

Fainbaum, Nadejda, and Claudio Sergio Batista. 2017. Malignancy Risk Index in Pelvic Mass Differentiation. J Gynecol Women's Health. 2(4): 555595.

Fauziah, I, and Andrijono Andrijono. 2007. The Study of Neoadjuvant Chemotherapy for Advanced Ovarian Carcinoma at Dr. Hospital. Cipto Mangunkusumo Year 2000-2005. Indonesian Journal of Obstetrics and Gynecology. $31: 2$

Loomis, Dana, Wei Huang, and Guosheng Chen. 2014. The International Agency for Research on Cancer (IARC) Evaluation of the Carcinogenicity of Outdoor Air Pollution: Focus on China. Chinese journal of cancer 33(4): 189.

Lu, F Kayikçiog et al. 2001. Neoadjuvant Chemotherapy or Primary Surgery in Advanced Epithelial Ovarian Carcinoma. International Journal of Gynecologic Cancer 11(6).

McGuire, Shelley. 2016. World Cancer Report 2014. Geneva, Switzerland: World Health Organization, International Agency for Research on Cancer, WHO Press, 2015. Advances in Nutrition 7(2): 418-19. https://doi.org/10.3945/an.116.012211.

Montes, Ana Fernández et al. 2012. Epidemiology and Etiology of Ovarian Cancer: A Review. Obstetrics and gynecology 66(1): 127-35.

Mutch, David G, and Jaime Prat. 2014. 2014 FIGO Staging for Ovarian, Fallopian Tube and Peritoneal Cancer. Gynecologic oncology 133(3): 401-4.

Ness, Roberta B et al. 2011. Contraception Methods, beyond Oral Contraceptives and Tubal Ligation, and Risk of Ovarian Cancer. Annals of epidemiology 21(3): 18896.

Nurseta, Tatit et al. 2020. Risk of Malignancy Index 4 (RMI4) and Risk of Malignancy Index 3 (RMI3) as Diagnostic Tests for Adnexal Tumor. Indonesian Journal of Obstetrics and Gynecology: 237-43.

Pignata, Sandro et al. 2011. Carboplatin plus Paclitaxel versus Carboplatin plus Pegylated Liposomal Doxorubicin as First-Line Treatment for Patients with Ovarian Cancer: The MITO-2 Randomized Phase III Trial. Journal of clinical oncology 29(27): 3628-35.

Terzic, $M$ et al. 2013. Predictive Factors of Malignancy in Patients with Adnexal 
Masses. Eur J Gynaecol Oncol 34(1): 65-69.

Ulusoy, $S$ et al. 2007. The Risk of Malignancy Index in Discrimination of Adnexal Masses. International Journal of Gynecology \& Obstetrics 96(3): 186-91.

Worley Jr, Michael J et al. 2013. Does Neoadjuvant Chemotherapy Decrease the Risk of Hospital Readmission Following Debulking Surgery? Gynecologic oncology 129(1): 69-73.

Yamamoto, Yorito et al. 2014. Comparison of 4 Risk-of-Malignancy Indexes in the Preoperative Evaluation of Patients With Pelvic Masses: A Prospective Study. Clinical Ovarian and Other Gynecologic Cancer 7(1): 8-12. https://www.sciencedirect.com/science/article/pii/S2212955314000623. 